Photogrammetry Journal of Turkey
Türkiye Fotogrametri Dergisi
https://dergipark.org.tr/tr/pub/tufod
e-ISSN 2687-6590

\title{
Harita mühendisliğinde İHA ile karayolu projelendirme
}

\section{Fatih Tükenmez}

Karayolları 5.Bölge Müdürlüğ̈̈, Etüt Proje ve Çevre Bașmühendisliği, Mersin, Türkiye

\author{
Anahtar Kelimeler: \\ İHA \\ Sayısal Arazi Modeli \\ Karayolu
}

\begin{abstract}
ÖZ
Karayolu projelerinin hazırlanması süreçlerinde proje altlı̆ğ olan Halihazır haritaların üretilmesi, karayolu proje güzergahlarını planlanması, projelerinin araziye uygulanması konularında Harita Mühendisleri önemli görevler almaktadırlar. Günümüzde modern ölçme sistemleri arasında yer alan İnsansız Hava Araçları (İHA)' lar, son zamanlarda birçok kulanım alanları olduğu gibi karayolu projelerinde de kullanılmaktadır. Karayolu projelerinde, proje güzergahı geometrik elemanlarının hesaplanması ve sonrasında toprak hareketi olarak da ifade edilen kazı dolgu miktarlarının (kübaj) belirlenmesi, proje altlığı olan sayısal hâlihazır haritaların doğruluğu ve hassasiyeti ile doğrudan ilişkilidir. Karayolu projelerine altlı üretilen sayısal halihazır haritaların sayısal arazi modelinin diğer yersel yöntemler ile üretilen haritalar ile karşılaștırıldığında istenilen hassasiyet de olduğu görülmekte olup zaman ve maliyet açısından da ele alındığında kamu kaynaklarının etkin ve verimli kullanılması yönünden İHA ların kullanılması önem arz etmektedir.
\end{abstract}

\section{Roadway projecting with UAV in survey engineering}

\author{
Keywords: \\ Ummanned Aerial Vehicle \\ Digital Terrain Model \\ Roadway
}

\begin{abstract}
Survey Engineers take important tasks in the preparation of highway projects, in the production of existing maps, which are the project base, in the planning of highway project routes, and in the implementation of their projects on the land. Unmanned Aerial Vehicles (UAVs), which are among the modern measurement systems today, have recently been used in road projects as well as in many areas of use. In highway projects, the calculation of the geometric elements of the project route, and then the determination of the amount of excavation fill (cubaj), which is also expressed as soil movement, is directly related to the accuracy and precision of the digital base maps, which are the project base. When the digital terrain model of the digital base maps produced as a base for highway projects is compared with the maps produced by other terrestrial methods, it is seen that the desired sensitivity is also seen, and it is important to use UAVs in terms of effective and efficient use of public resources when considered in terms of time and cost.
\end{abstract}




\section{Giriş}

Ulaşım, genel olarak yolcuların ve eşyaların yer değiştirmesi olarak tanımlanmaktadır. Ulaşım yollarından birisi olan karayolu ise; yolcuların ve eşyaların güvenli, hızlı, konforlu bir şekilde taşınması için trafik akışına imkân sağlamak üzere kamunun yararlanmasına açık olan arazi şeritleridir. Bir karayolu üzerinde; köprüler, tüneller, menfezler, viyadükler vs. gibi sanat yapıları bulunmaktadır. Karayollarının geçmişte olduğu gibi günümüzde de toplumların kalkınmalarında ve refaha ulaşmalarında büyük payı bulunmaktadır. Büyük bir yatırımla gerçekleştirilen bu sistemin ülke ekonomisine katkıda bulunabilmesi için karayolu güzergahının uygun seçilmesine, yapım, bakım ve işletme masraflarının düşük olmasına dikkat edilmelidir. Bu bakımdan karayolunu kullananlara onu teşkil eden ögelerinin çok iyi etüt edilmesine ve bilinmesine ihtiyaç vardır.

Ulaşım Mühendisliği (Yol Mühendisliği) son zamanlarda karayolu projelendirme ve yapım konularında ele alındığında kendi başına bir bilim dalı olarak görülmektedir. Bu yönüyle yol (ulaşım) mühendisliği; Harita mühendisliği, inșaat mühendisliği, jeoloji, jeofizik, çevre mühendisliği ve şehir planlaması gibi bilim dallarının ve mesleklerin temel mühendislik bilgilerini kullanan bir mühendislik bilim dalıdır. (Kök 2019).

Harita ve Harita Mühendislik hizmetleri tüm yatırım ve mühendislik hizmetlerinin altyapısını oluşturmaktadır. Karayolu projelerinde de harita mühendislerinin yoğun ve önemli ișlevleri vardır. $\mathrm{Bu}$ bakımdan Karayolları teşkilatında çalıșan harita mühendisleri güzergâh etüdü, sayısal hâlihazır harita üretilmesi, aplikasyon (piketaj), yol platformunun teşkil edilmesindeki tüm aşamalardaki arazi çalışmalarında, halihazır haritaların tamamlanmasına müteakip uygun yazılımlar kullanılmak suretiyle uygulama projesi çalışmalarında (plan, profil, enkesit, kübaj hesabı vb.) görev almaktadırlar.

Yakar ve ark. 2005, Harita mühendislerinin günümüzde kültürel mirasın belgelenmesi çalışmalarında da çağdaş teknolojinin bir ürünü olan İHA kullanarak etkin bir görev almalarını öngörmüşlerdir.

Karayolu projelerine altlık olarak kullanılan halihazır haritalar, yaklaşık 200 m genişliğinde bir koridoru kapsayan alanda üzerinde dere, tepe, yol, $\mathrm{ENH}$, vs. yapıların gösterildiği şeritvari haritalardır. Söz konusu halihazır haritalarda karayolu proje güzergahlarında kritik arazi kesiti olarak tanımlanan dere, hendek, şev gibi kesitlerin gerçek araziyi yansıtması ve toprak hacim miktarlarının doğru hesaplanması için halihazır harita sayısal yükseklik modeli hassasiyetinin yüksek doğrulukta olması önem arz etmektedir.

Günümüzde İHA (İnsansız Hava Araçlarının) gelişen teknoloji ile birlikte hızla gelişmesi, beraberinde bu araçların kullanım yelpazesini oldukça genişletmiş çok farklı meslek disiplinlerinde yerini almıştır (Yakar ve Mırdan 2017). İHA Fotogrametrisi yöntemleri ile üretilen sayısal hâlihazır haritalar ve SAM (Sayısal Arazi Modeli) karayolu projelerinde arzu edilen hassasiyeti gösterdiği görülmektedir.

Sayısal arazi modeli, insan yapısı detayları ve bitki örtüsü gibi detayların olmadığı çıplak yer yüzeyi olarak tanımlanmaktadır (Höhle, 2009).

Sayısal arazi modeli karayolu projelendirme sürecinde yatay ve düşey güzergâhın sağlıklı bir şekilde belirlenmesi ve yapım maliyetlerini doğrudan etkileyen toprak işi miktarının hesaplanmasında ciddi bir öneme sahiptir (Tercan E.,2017).

Diğer bir ifade ile SAM; arazi üzerindeki doğal ve yapay unsurlar çıkarıldıktan sonra kalan çıplak yer yüzeyini belirtmektedir (Uysal ve ark. 2015).

Karayolu, insan eliyle insanlığa yapılan en önemli altyapı yatırımlarından birisi olup insanoğlunun ortak mekânı, toplumların ileriye yolculuğudur. Yolların tarihi ilk insanla başlar, geçmişten geleceğe doğru gelişerek uzar gider. $\mathrm{Bu}$ nedenle yol; bir ülkenin kalkınmasına, toplumun sosyo-ekonomik gelişimine temel oluşturan en önemli altyapıdır.

Tekerleğin bulunması uygarlık tarihinin en önemli aşamalarından birisidir. Ancak tekerleğin asıl önemi, ulaştırma alanında ortaya çıkmıştır. Tekerlek önceleri önemli taşıt aracı olan kızağa uygulanmıştır. Kızaktan sonra uygulanan iki veya dört tekerlekli arabalar, M.Ö. 2000 yıllarında ortaya çıkmıştır. Böylelikle ilk arabalar askeri ve ticari açıdan önemli rol oynamıştır (URL-1).

Yollar tarihsel olarak ele alındığında Osmanlı Döneminde ve kuruluş yıllarında Selçuklu, Bizans ve Roma yolları kullanılmıştır. Ancak ticaret ve siyasi merkezlerin değișmesi sonucu kıyı şehirlerinden limanlardan Anadolu'nun içlerine giden yeni yollar açılmıştır. Osmanlı zamanında öncelikli olarak savaş zamanı öncesi yolları yapılmış olup barıș zamanında yol yapımı durmuştur. Yol yapımında sadece yol yapıcı olarak ifade edilen kaldırımcılar değil, bölgenin işe yarar bütün elemanları seferber edilirdi (Şekil 1.)

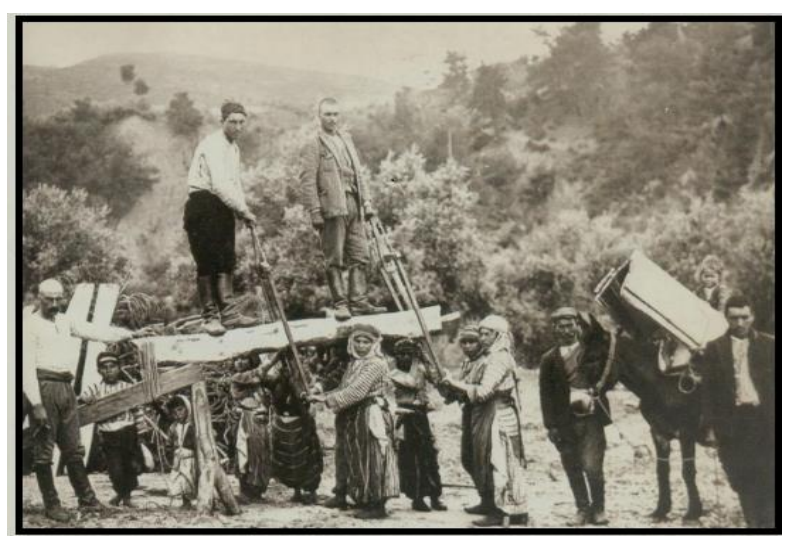

Şekil 1. Osmanlı Dönemi Yol Çalışmaları [URL-1]. 
Cumhuriyet Döneminde ise; Cumhuriyetin kuruluşuyla ülkemizdeki yol ve köprü ihtiyacını belirlemek ve bununla ilgili olarak gerekli tedbirlerin alınmasını sağlamak amacıyla konu üzerinde çalışmalar yapılmıştır. Sonrasında Milli Şoseler ve Köprüler Kanunu hazırlanarak Karayolu hizmetleri için Nafia Vekaletine bağlı Nafia Dairesi kurulmutur.1950 yılında ise Bayındırlık Bakanlığına bağlı olarak Karayolları Genel Müdürlüğü kurulmuştur. Karayolları Genel Müdürlüğü sorumluluğunda 2020 yll itibariyle $3.060 \mathrm{~km}$ Otoyol, $31.06 \mathrm{~km}$ devlet yolu, $34.165 \mathrm{~km}$ il yolu olmak üzere toplam 68.211 karayolu ağı bulunmakta olup yaklaşık $25 \mathrm{~km}$ si bölünmüş yoldur (KGM 2006).

1950-1970 yılları arası karayolu yapımının altın çağı olmuștur. $\mathrm{Bu}$ dönemde yol yapım politikalarının ana amacı; sağlık, eğitim gibi temel hizmetlerin ülkenin tüm yörelerine götürülebilmesi için yaz kış geçit verilebilecek yoları tesis etmek olmuștur. Ancak "teker dönsün" mantığıyla ülkenin her yerine ulaşabilmek amacıyla yapılan bu yolların geometrik ve fiziki standardı oldukça düşüktür (KGM 2006).

Geçmiş ylllarda klasik yöntemle karayolu proje çalıșmalarında aşağıda belirtilen yöntemler uygulanirdı.

$\mathrm{Bu}$ yöntemle karayolu güzergâh projelerinde etüt haritaları tamamlanan güzergâh üzerinde öncelikle güzergâh araştırması yapılırdı. Yol güzergahı araştırmasında, geçilecek yerlerin tespitinde verilen eğim kriterlerine göre sıfır poligonu geçirilir. Sıfır poligonu, tabi zemine en uygun verilen eğime uygun en az kazı gerektirecek olan hattır (Şekil 2).

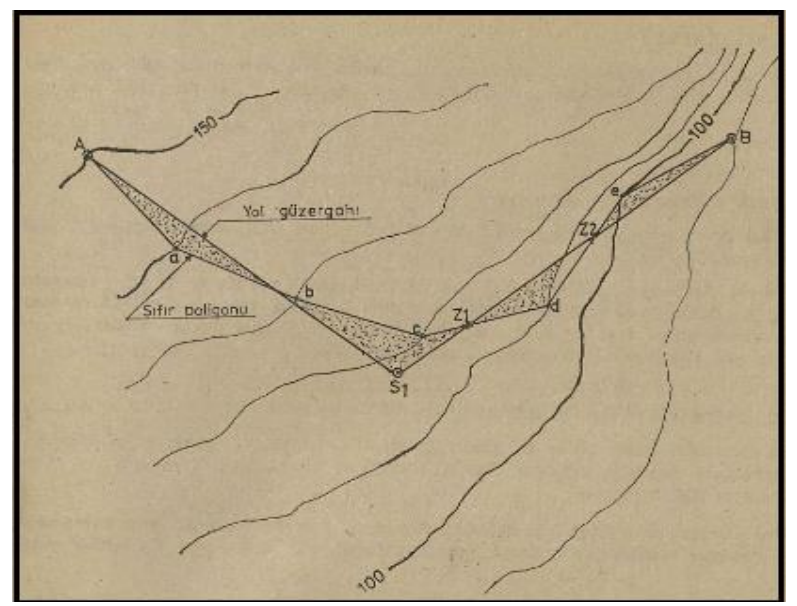

Şekil 2. Sıfır Poligonu [URL-1].

Karayolu tasarım kriterlerine göre etüt haritası üzerine çizilen güzergâh yatay hattın (șekil 3) araziye aplikasyonu yapılır. Yapılan bu aplikasyon (piketaj) çalışmasında (Some noktası aplikasyonu, eksen nivelmanı (boykesit) ve enkesit alımından oluşmaktadır.

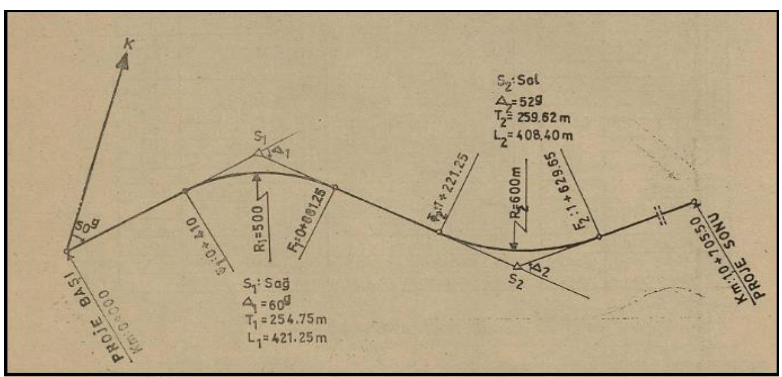

Şekil 3. Aplikasyon Hattı [URL-1].

Güzergâh ekseni üzerinde alınan kesit boykesittir. Güzergâh aplikasyonu tamamlandıktan sonra 1/1000 yatay, $1 / 100$ düşey ölçeğinde boykesit çizimi yapılır (Şekil 4).

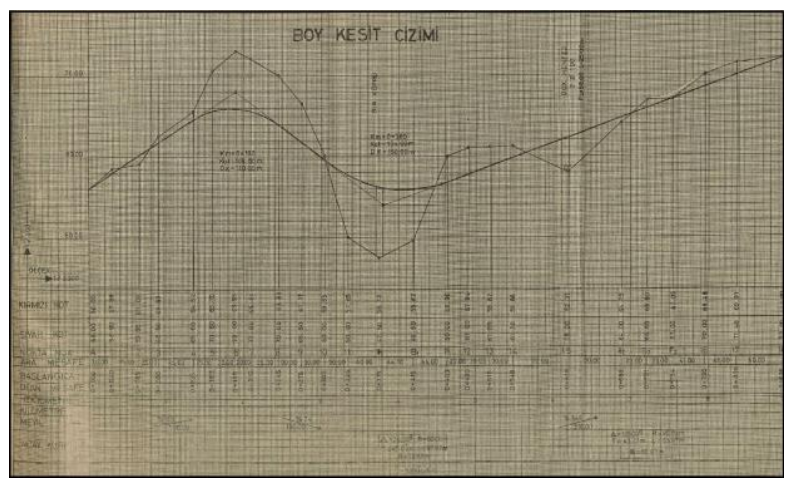

Şekil 4. Boykesit [URL-1].

Etüt haritası üzerinde veya genellikle arazide alınan enkesit alımları sonucu eksen km üzerinde $20 \mathrm{~m}$ de bir genellikle yatayda ve düşeyde $1 / 100$ ölçeğinde enkesit çizimi yapılır (Şekil 5).

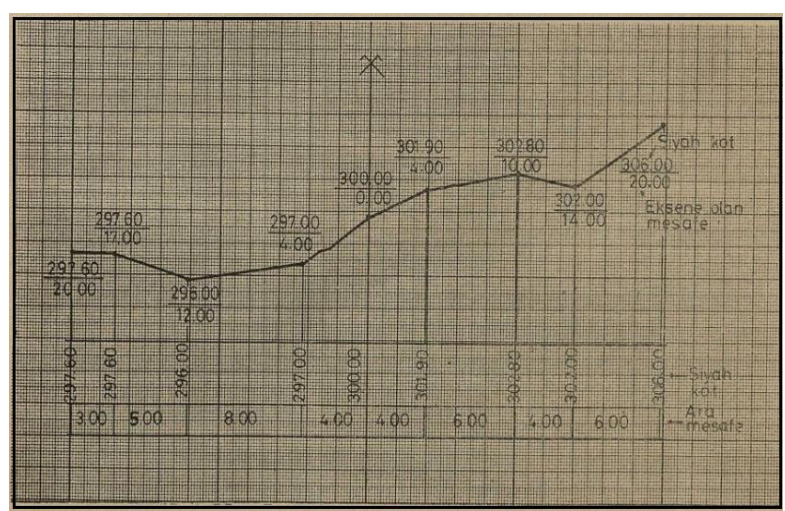

Şekil 5. Enkesit [URL-1].

Bir yol projesinde boykesite ait arazi (siyah) hattı çizildikten sonra sanat yapıları, zemin araştırmaları ve belirlene yol standartlarına göre kırmızı hat çalışması yapılır. Kırmızı hat bir seri doğru parçaları ile birbirine bağlanmış eğrilerden (düșey kurb) (parabolik eğri) olușmaktadır. Kırmızı hat çalınmalarında eğim ve tasarım hızı, görüș mesafesi, kazı ve dolgu miktarlarının birbirini dengelemesi, akarsu ve feyezan sahaları geçişlerinde su kotundan yüksek olması gibi kriterler dikkate alınmaktadır.

$\mathrm{Bu}$ aşamalardan sonra yatay hat üzerinde bulunan yatay kurbların dever ve rakortman boyu hesabı yapılır. Dever; yatay kurplarda taşıtların 
hızlarından dolayı meydana gelebilecek merkezkaç kuvvetini yenmek araçların devrilme ve kaymalarını önlemek için yol platformuna verilen eğimdir.

$\mathrm{S}=0.00443 \mathrm{~V} 2 / \mathrm{R} \quad \mathrm{S}=$ Dever $(0.08$ den büyük olamaz), V=Proje hızı, R= Kurb yarıçapı, Ls=0.0354V3/R Ls= Dever Rakordman boyu $(45 \mathrm{~m}$ den küçük olamaz). Yol kırmızı kotu, dever ve rakortman boyları ve hesaplandıktan sonra yol en kesitleri çizimi yapılır. Bu enkesit tipleri, Dolgu, yarma ve karışık (mix) kesit şeklinde olmaktadır (Şekil 6).

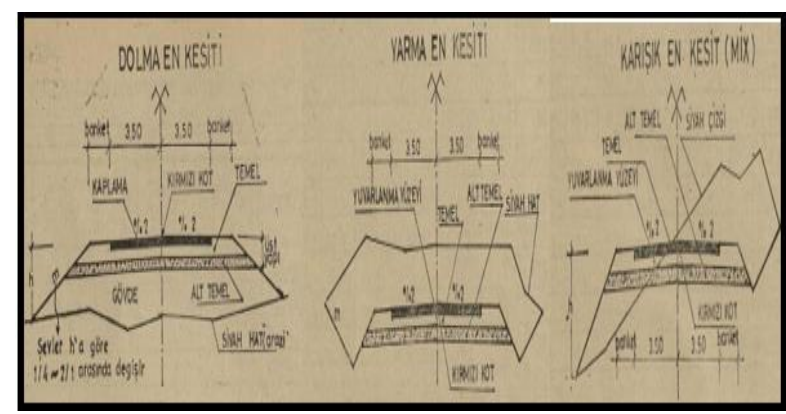

Şekil 6. Enkesit Tipleri [URL-1].

Yol güzergahı boyunca kazı dolgu miktarlarını hesaplayabilmek için enkesitlerden alan hesabı yapılmaktadır. Kesit alanlarının hesaplanmasında grafik metodlar, planimetre ile ölçme ve cebrik (cross) metodu kullanılmaktadır. Yol inşaatının maliyetini hesaplanması için yolda yapılacak kazı ve dolgu miktarlarının bilinmesine ihtiyaç vardır. Hacim hesapları da enkesit alanları ve bu kesitler arası mesafeden yararlanarak hesaplanır (Şekil 7).

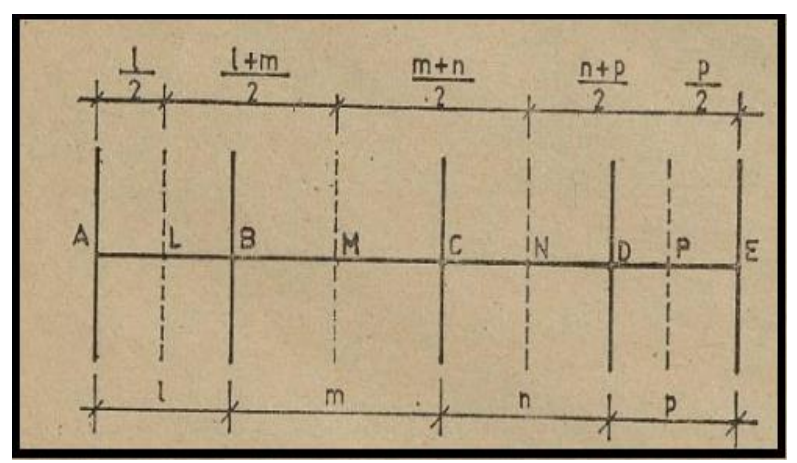

Şekil 7. Hacim Hesapları [URL-1].

$\mathrm{V}=(\mathrm{A}+\mathrm{B}) / 2 \mathrm{XL}+(\mathrm{B}+\mathrm{M}) / 2 \mathrm{XM}+(\mathrm{C}+\mathrm{D}) / 2 \mathrm{XN}+(\mathrm{D}+\mathrm{E}) /$ 2XP formulü ile hacim hesaplanır. Tesviye işlerinin miktarlarını hesaplayabilmek için kübaj cetvelleri düzenlenir. Kübaj cetvelleri boykesit ve enkesit hesaplarından yararlanılarak doldurulur (Şekil 8).

Brükner; yarmadan dolguya veya ariyet den dolguya, yarmadan depoya yapilacak en ekonomik taşımaları ve bunların mesafelerinin grafik gösterimidir. (Șekil 9). Diğer bir ifadeyle; kübaj tablosunda her kesitteki artan kazı ve dolgu hacimlerinin yol başlangıcından başlamak üzere cebrik toplamlarının kazı (+), dolgu (-) alınarak bulunan değerlerin, kesitlerin gösterildiği bir eksende ordinat olarak alınmasıyla bulunan kırık doğru parçalarının tümüne denir.

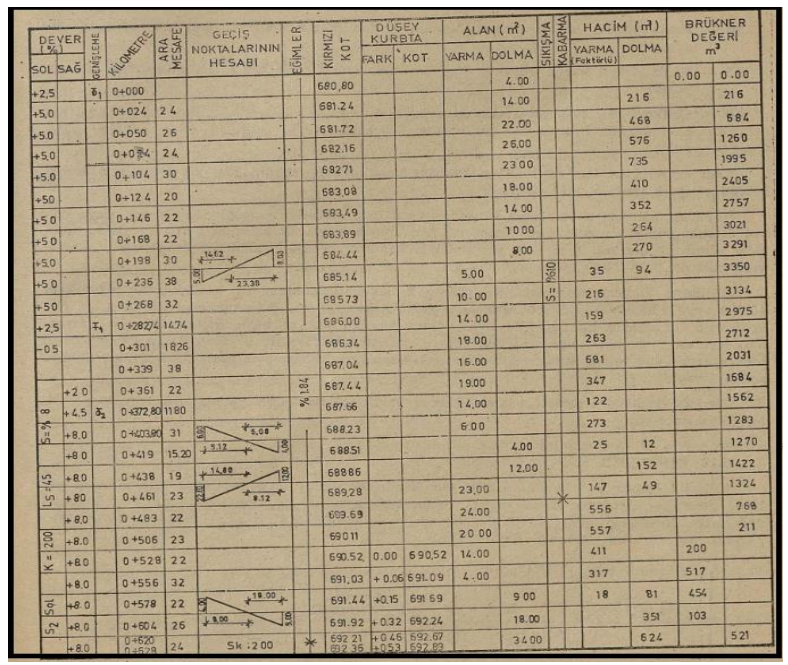

Şekil 8. Kübaj Cetveli [URL-1].

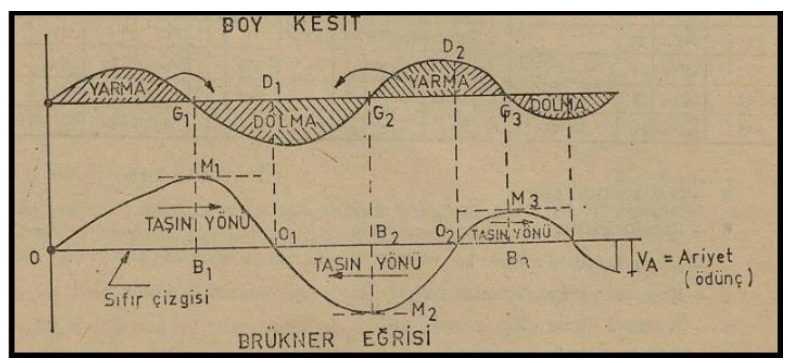

Şekil 9. Brükner Eğrisi [URL-1].

Günümüzde ise öncelikle karayolu proje güzergahının 1/25000 ölçekli güzergâh planı üzerinden geçki tasarımı yapılmaktadır (Şekil 10).

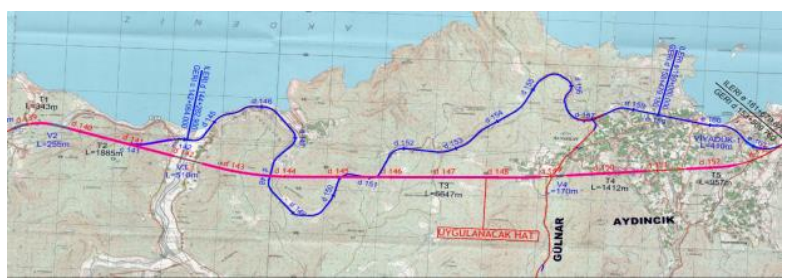

Şekil 10. 1/25000 ölçekli güzergâh kılavuz planı

Güzergâh geçki tasarımı kesinleşen hat üzerinden Proje güzergâh geometrik elemanları oluşturulur ve hesaplanır. Proje Geometrik elemanları ana hatlarıyla Yatay Geometri (Plan), Düşey Geometri (Profil), dever ve enkesit den oluşmaktadır. Karayolu geometrik elemanları tasarımında Karayolları Genel Müdürlüğü tarafindan onaylanan Karayolu Geometrik Standartları esas alınmaktadır.

Karayolu geometrik standartlarına göre belirlenen geometrik elemanlar tamamlandiktan sonra yolun sınıfına göre uygulanacak enkesit tapine karar verilir ve daha sonra yol projelendirme yazılımları kullanılarak güzergahın şevli planı (modelleme) oluşturulur (Şekil 11). 


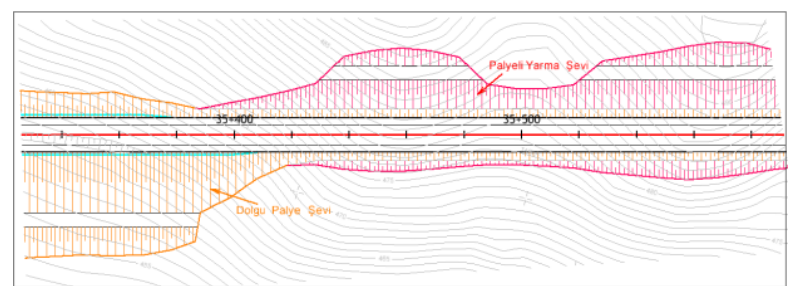

Şekil 11. Şevli Plan

Karayolu güzergâh projelerinde ayrıca güzergâh boyunca Hidrolik ve Hidrolojik etütler yapılarak yağış havza alanları belirlenir. Hesaplanan yağış debisine göre dere hattının karayolu güzergahını kestiği noktada olması gereken minimum menfez boyutları hidrolik hesaplama sonucu belirlenir. (SSekil 12).

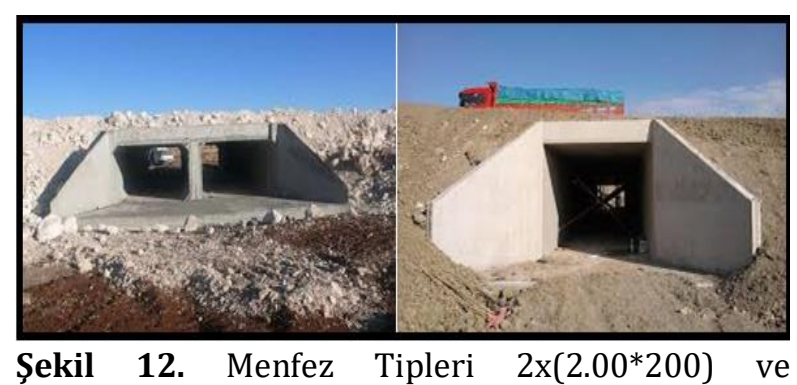

$(2.00 \times 2.00)$

\section{Materyal ve metot}

\subsection{Materyal ve veriler}

Son yıllarda İHA (İnsansız Hava Aracı) teknolojisinin gelişmesi ile yersel fotogrametri, yerini İHA fotogrametrisine bırakmıștır (Yiğit ve Uysal 2021; Korumaz ve ark. 2011). Dağlık ve erişemeyen alanlarda da DSM (Dijital Surface Model) oluşturmak için İHA kullanılabilmektedir Alptekin ve ark. 2019. İHA kullanılarak yol projeleri üretiminin yanısıra, heyelan bölgelerinin $3 \mathrm{~B}$ modellenmesi (Alptekin ve Yakar, 2020) ve kıyl kenar çizgisi belirleme (Unel ve ark. 2020) çalışmaları da yapılabilmektedir.

Karayolu projelerine altlık oluşturan sayısal halihazır haritalar yersel klasik, fotogrametrik ve son zamanlarda İHA fotogrametrisi ile üretilmektedir. Son zamanlarda birçok kullanım alanı bulunan İHA ların karayolu mühendisliği hizmetlerinde karayollarında da kullanılması önem arz etmektedir. Karayolu proje yatay ve düşey geometrisinin belirlenmesi ve yol yapım çalışmalarının yanında heyelan önleme projeleri ve kavşak alanları halihazır haritalarının üretilmesi gibi konularda da İHA lar (Şekil 13). Kullanılabilmektedir.

TUDKA (Türkiye Ulusal Düșey Kontrol Ağı) hattı üzerinde arazide mevcut tesisleri (en az 2 adet) tespit edilerek Helmert Ortometrik Kot değerleri Harita Genel Müdürlüğü'nden temin edilmektedir (Şekil 14,15). Daha sonra bu iki nokta arasında GPS nivelmanı veya Geometrik nivelman yapılarak bu noktaların doğruluğu test edilir.

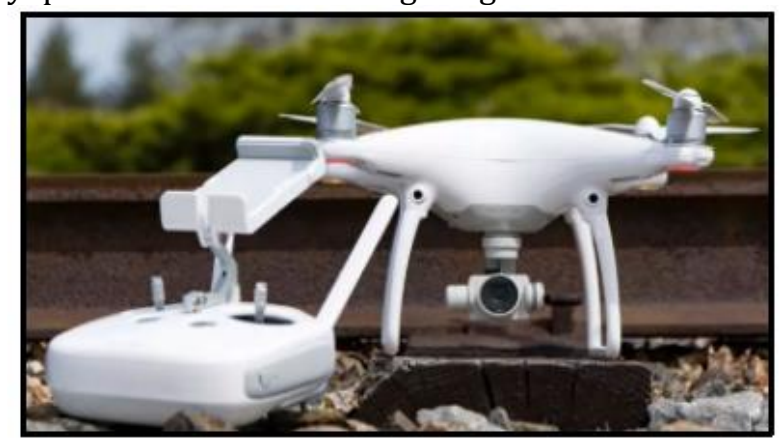

Şekil 13 DJI Phantom 4 Pro model drone [URL-2].

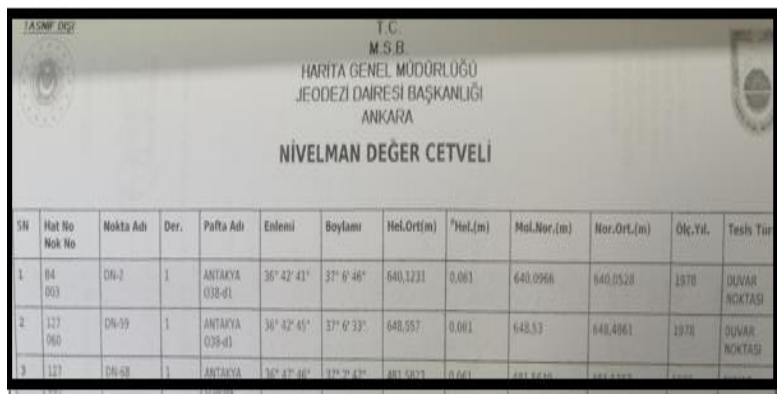

Şekil 14 Nivelman Değer Cetveli

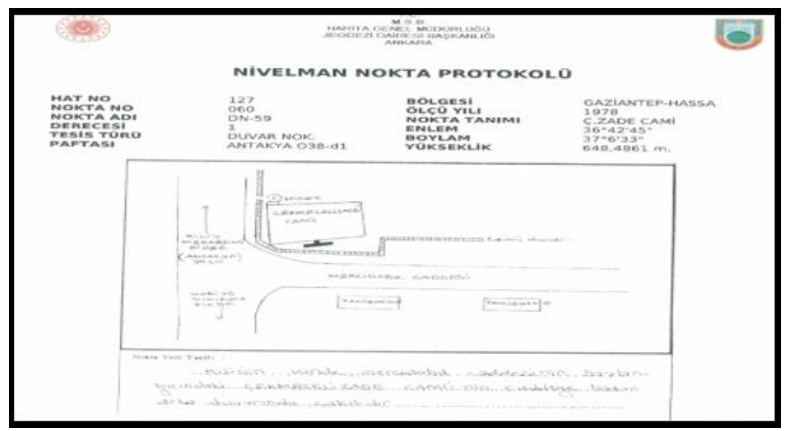

Şekil 15. Nivelman Nokta Protokolü

\subsection{Yöntem}

İstikşaf; Halihazır harita güzergahı üzerinde varsa mevcut yer kontrol ve nivelman noktaları ile yeni tesis edilecek olan YKN (Yer Kontrol Noktaları) (Nirengi veya Poligon) ile Nivelman noktalarının belirlenmesine yönelik arazide yapılan bir ön çalışmadır. Bu aşamada öncelikli olarak güzergâh üzerinde mevcut YKN olup olmadığının kontrolü sağlanarak, yeni yapılacak olan YKN tesislerinin arazideki yerleri yaklaşık olarak belirlenmiş olur.

YKN Tesisi ve Ölçümü; Yapılan istikşaf çalışması neticesinde arazide YKN tesisi yapılmıştır. Nokta tesisleri yapılırken etrafında ağaç, duvar, bina gibi havadan görünmesini engelleyecek yüksek yapının olmamasına dikkat edilmektedir. (Şekil 16.)

YKN lerin kolon baş ve sonlarına çift olmak üzere uçuş blok yapısına uygun tasarlanmasına dikkat edilmektedir.

Yapılan ölçülerde çift frekanslı GNSS alıcıları kullanılmaktadır. Olabilecek anten yüksekliği hatalarını önlemek amacıyla tüm noktalarda sabit 2 
m yükseklikli jalonlar kullanılarak ölçü başlangıç ve sonunda düzeçlerin kontrol edilmektedir.

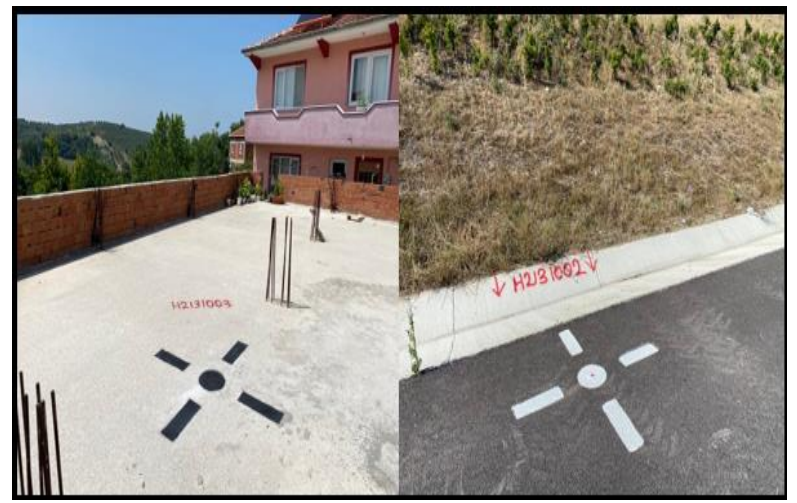

Şekil 16. YKN Tesisi

YKN' ler üzerinde en az 2 şer saat olmak üzere statik oturumlar yapılarak tüm noktaların ITRF 96 datumuna bağlanması amacıyla ülke koordinat sisteminde ITRF 96 koordinatları bilinen çalışma alanına yakın TUSAGA-Aktif Sabit GNSS istasyonları referans olarak kullanılmaktadır. Arazide elde edilen veriler büro ortamında bilgisayara aktarllarak, nokta ve anten yükseklikleri ile ölçü süreleri kontrol edilmektedir.

Datalar bilgisayar ortamına aktarıldıktan sonra baz çözümleri yapılmaktadır. Baz çözümleri sonuçları irdelenerek, varsa çözümü olumsuz etkileyen zaman aralıkları ve uydular tespit edilerek çözüm dışı bırakılmaktadır. Baz çözümlerinden sonra olușan üçgen kapanmaları irdelenerek BÖHHBÜY (Büyük Ölçekli Harita ve Harita Bilgileri
Üretim Yönetmeliği)'ne göre üçgen kapanma değerlerinin altında kalması gerekmektedir.

Baz çözümleri ve üçgen kapanmalarından sonra TUSAGA-Aktif Sabit GNSS İstasyonları' nın yıllık hız değişim vektörleri kullanılarak yapılan hesaplama ile elde edilen ölçü epok (2020.43) değerleri değişmez alınarak tüm ağ dayalı dengelenerek proje kapsamında yeni üretilen tüm YKN lerin ölçü epok koordinat değerleri elde edilir. (Tablo 1.) Dengeleme öncesi ağl kendi içerisinde kontrol etmek için, dengelemeyi güncel hızlara göre değerlendirilmesi için ölçü epok kaydırma işlemi gerçekleştirilir.

Ölçü epok koordinatları elde edilen YKN' lerin TUSAGA-Aktif Sabit GNSS İstasyonu yıllık hız değișim vektörleri kullanılarak yapılan ağırlıklı enterpolasyon hesabı ile proje kapsamında yeni üretilen C3 derece YKN' lerin yıllık hız değișim vektörleri ve 2005.00 referans epok koordinat değerleri hesaplanır. (Tablo 2).

Uçuş planı; güzergahın arazi yapısı, kamera özellikleri hava aracının teknik özellikleri vs. ve teknik şartnamede belirtilen yer örnekleme aralığ GSD (Ground Point Control) alınarak hazırlanan kolonlardan oluşan (şekil 17) plandır.

Uçuş planında özellikle kolonları baş ve sonlarında, iki kolonun kesişim yerlerinde en az 2 YKN olmasına dikkat edilmektedir. Uçuş işleminde, döner kanatlı PPK özelliği kullanılan İHA lar tercih edilmektedir. Uçuş yüksekliği, bindirme oranları, uçuş saati aralığl, GSD çözünürlüğü gibi kriterler teknik şartnamede belirtilmektedir.

Tablo 1. Epok Kaydırma İşlemi

TUSAGA AKTİF NOKTALARINI ÖLÇÜ EPOĞUNA KAYDIRMA HESABI

\begin{tabular}{|c|c|c|c|c|c|c|c|}
\hline ORTALAMA & \multicolumn{2}{|c|}{06.06 .2020} & Artık yil & \multicolumn{2}{|l|}{0.43} & \multirow{2}{*}{$\begin{array}{l}\text { DATUM } \\
\text { Elipsoid }\end{array}$} & \multirow{2}{*}{$\begin{array}{l}\text { ITRF96 } \\
\text { GRS } 80\end{array}$} \\
\hline ÖLÇÜ YILI & 2020 & & Ölçü Epok & 2020.43 & & & \\
\hline REFERANS EPOK & 2005.00 & \multicolumn{2}{|c|}{ Epok Kaydırma Miktarı } & 15.43 & & & \\
\hline N.No & $\mathbf{x}$ & $\mathbf{y}$ & $\mathbf{z}$ & $\mathbf{V x}$ & Vy & $\mathbf{V z}$ & Epok \\
\hline ONIY & 4107230.2465 & 3011971.0015 & 3826521.2625 & -0.01814 & 0.00406 & 0.01225 & 2005 \\
\hline MAR_1 & 4048981.8907 & 3035809.1080 & 3870228.8971 & -0.0187 & 0.00469 & 0.01425 & 2005 \\
\hline KLIS & 4048981.8907 & 3035809.1080 & 3870228.8971 & -0.0187 & 0.00469 & 0.01425 & 2005 \\
\hline HAT1 & 4048981.8907 & 3035809.1080 & 3870228.8971 & -0.0187 & 0.00469 & 0.01425 & 2005 \\
\hline ANTE & 4048981.8907 & 3035809.1080 & 3870228.8971 & -0.0187 & 0.00469 & 0.01425 & 2005 \\
\hline N.No & $\mathbf{x}$ & $\mathbf{y}$ & $\mathbf{z}$ & $\mathbf{V x}$ & Vy & $\mathbf{V z}$ & Epok \\
\hline ONIY & 4107230.2465 & 3011971.0015 & 3826521.2625 & -0.01814 & 0.00406 & 0.01225 & 2020.43 \\
\hline MAR_1 & 4048981.8907 & 3035809.1080 & 3870228.8971 & -0.0187 & 0.00469 & 0.01425 & 2020.43 \\
\hline KLIS & 4048981.8907 & 3035809.1080 & 3870228.8971 & -0.0187 & 0.00469 & 0.01425 & 2020.43 \\
\hline HAT1 & 4048981.8907 & 3035809.1080 & 3870228.8971 & -0.0187 & 0.00469 & 0.01425 & 2020.43 \\
\hline ANTE & 4048981.8907 & 3035809.1080 & 3870228.8971 & -0.0187 & 0.00469 & 0.01425 & 2020.43 \\
\hline ONIY & 4107230.2465 & 3011971.0015 & 3826521.2625 & -0.01814 & 0.00406 & 0.01225 & 2020.43 \\
\hline
\end{tabular}


Tablo 2. YKN Referans Epok Koordinat Değerleri

\section{C3 NOKTALARINI REFERANS EPOĞUNA KAYDIRMA HESABI}

\begin{tabular}{|c|c|c|c|c|c|c|c|}
\hline ORTALAMA & \multicolumn{2}{|c|}{06.06 .2020} & Artık yıl & 0.43 & & \multirow{2}{*}{$\begin{array}{l}\text { DATUM } \\
\text { Elipsoid }\end{array}$} & \multirow{2}{*}{$\begin{array}{l}\text { ITRF96 } \\
\text { GRS } 80\end{array}$} \\
\hline ÖLÇÜ YILI & 2020 & & Ölçü Epok & 2020.43 & & & \\
\hline REFERANS EPOK & 2005.00 & Epok Kaydırma N & ktarı & 15.43 & & & \\
\hline N.No & $\mathbf{x}$ & $\mathbf{y}$ & $\mathbf{z}$ & $\mathbf{V x}$ & Vy & $\mathbf{V z}$ & Epok \\
\hline 03730305 & 4107230.2465 & 3011971.0015 & 3826521.2625 & -0.01814 & 0.00406 & 0.01225 & 2020.43 \\
\hline 03730306 & 4048981.8907 & 3035809.1080 & 3870228.8971 & -0.0187 & 0.00469 & 0.01425 & 2020.43 \\
\hline 03730307 & 4048981.8907 & 3035809.1080 & 3870228.8971 & -0.0187 & 0.00469 & 0.01425 & 2020.43 \\
\hline 03830434 & 4048981.8907 & 3035809.1080 & 3870228.8971 & -0.0187 & 0.00469 & 0.01425 & 2020.43 \\
\hline 03830435 & 4048981.8907 & 3035809.1080 & 3870228.8971 & -0.0187 & 0.00469 & 0.01425 & 2020.43 \\
\hline 03830439 & 4107230.2465 & 3011971.0015 & 3826521.2625 & -0.01814 & 0.00406 & 0.01225 & 2020.43 \\
\hline 03830442 & 4048981.8907 & 3035809.1080 & 3870228.8971 & -0.0187 & 0.00469 & 0.01425 & 2020.43 \\
\hline 03830443 & 4048981.8907 & 3035809.1080 & 3870228.8971 & -0.0187 & 0.00469 & 0.01425 & 2020.43 \\
\hline 03830437 & 4048981.8907 & 3035809.1080 & 3870228.8971 & -0.0187 & 0.00469 & 0.01425 & 2020.43 \\
\hline
\end{tabular}

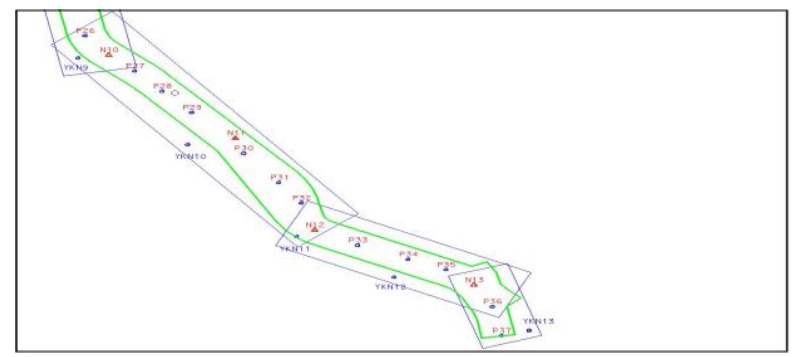

Şekil 17. Uçuş Planı

Uçuş yapılan kolona en yakın YKN ye GPS kurularak statik ölçü yapılmaktadır. Bu durum resim koordinatlarının hassas hesaplanmasını sağlamaktadır. Böylece hem PPK çözümü hem de YKN değerleri kullanılarak resim orta koordinatları ve dönüklükleri en hassas şekilde elde edilmektedir.

Havai Nirengi Dengeleme; Elde edilen resimlerin PPK çözümleri yapılarak havai nirengi işlemlerine geçilir. $\mathrm{Bu}$ işlem ise Örn: Agisoft Metashape 1.5.2 gibi yazılımlar kullanılarak yapılmaktadır. Öncelikli olarak fotoğraflar arasında bağlama noktaları toplanarak modellerin ve kolonları birbirleri ile relative bağlantısı sağlanmıștır (Şekil 18). Sonrasinda ise YKN ler fotoğraf üzerinde işaretlenerek mutlak dengeleme yapılmıştır (Şekil 19).

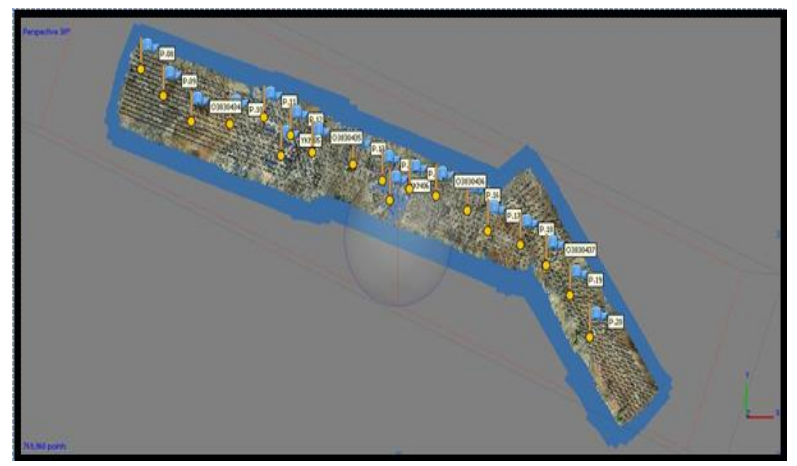

Sekil 18. Fotoğraf bağlama ișlemi sonrası görüntü

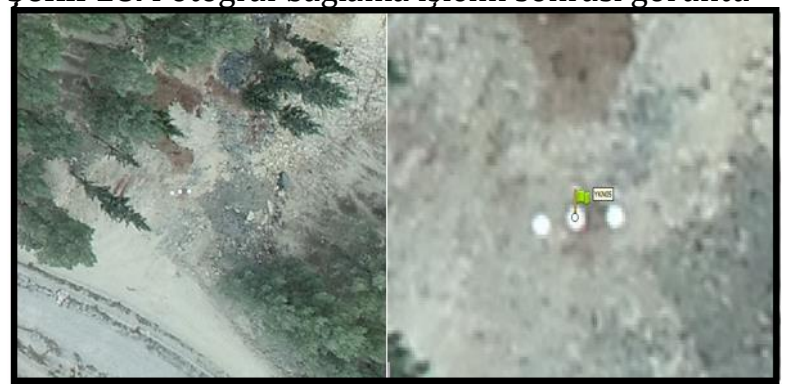

Şekil 19. YKN lerin model üzerindeki işaretleri

Proje üzerindeki tüm YKN lerin işaretlemeleri bu şekilde yapılarak dengeleme işlemi tamamlanır.

Sayısallaştırma; Havai nirengi sonrasında elde edilen resim orta nokta koordinatları ile dönüklükleri ve kamera kalibrasyon değerleri kullanılarak sayısallaştırmaya yönelik blok dosyası oluşturulur. Sayısallaştırma işlemi tecrübeli operatörler tarafından 3B gözlük ve emitter kullanılarak yapılmaktadır. Yol, dere, duvar, bina, çit gibi tüm yapılar sayısallaştırılmıştır. Ayrıca araziyi yansitan DTM noktaları manuel olarak yine operatörler tarafından üretilmiştir. Arazideki sırt kısımları breakline olarak çizilerek üçgen modele dahil edilmektedir. Sayısallaştırma için Leica Photogrammetry Suite (LPS) yazılımı ve bununla entegre çalışabilen MicroStation V8i eş zamanlı olarak kullanılmaktadır.

Operatörler tarafindan kıymetlendirmesi yapılan tüm modeller tek bir dosyada birleştirilerek bütün harita haline getirilmektedir. Sonraki çalışmalar bu şekilde tüm veri üzerinden devam ettirilmiştir. Bu aşamada kıymetlendirme esnasında yapılmayan, şev tarama, bina kat adedi belirleme, eğri geçirme, eğrilerin temizlenmesi gereken detayların kapalı alan haline getirilmesi, cadde-sokak isimlerinin tespiti ve haritaya işlenmesi, resmi yapıların 
isimlerinin işlenmesi, üçgen model (Sayısal Arazi Modeli) oluşturulması gibi adımlar tamamlanmaktadır.

Karayolu projelerine altlık olarak kullanılan sayısal arazi modeli (SAM), İHA fotogrametrisiyle oluşturulan yoğun nokta bulutu ve bu nokta bulutunun sinıflandırması sonucu da elde edilebilmektedir. Uygulamada nokta bulutu sınıflandırmasını (arazi yüzeyindeki bitki örtüsü, ormanlık alanlar, binaların vs. alanların sayısal arazi modeline dahil edilmemesi) yapan yazılımlara Pix4D ve Agisoft yazılımları örnek olarak verilebilir. $\mathrm{Bu}$ yazılımlar kullanıcı kolaylığı ve hızlı olması bakımından daha çok tercih edilmektedirler.

Ortofoto; Kısaca ölçeklendirilmiş, üzerinden ölçü alınabilen resimli plan olarak tanımlanmaktadır. Resimlerdeki resim eğikliğinin ve arazideki yükseklik farklarından kaynaklı görüntü kaymalarının giderilmesi sonucu elde edilen ölçekli fotoğraf görüntüdür (Şekil 20). Dengeleme ve DTM üretiminden sonra ortofoto, ecw formatında üretilmektedir. GSD (Yer Örnekleme Aralığı) 7 cm'dir.

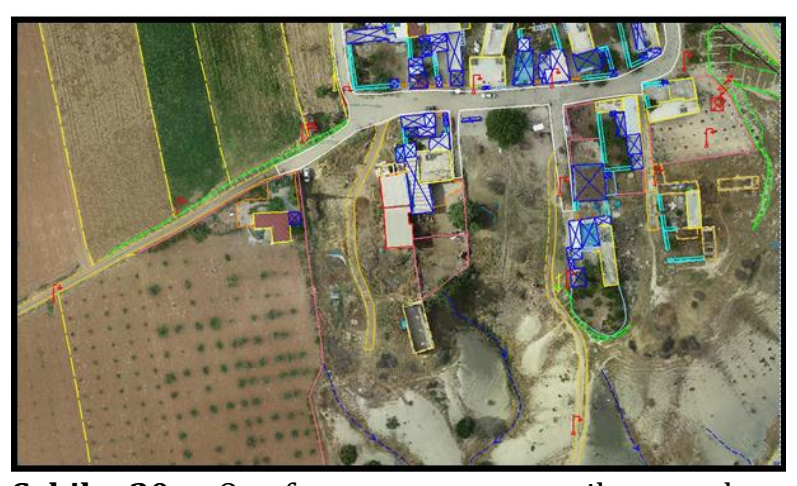

Şekil 20. Ortofoto ve stereo ile yapılmış kıymetlendirme

Karayolları 5.Bölge sorumluluk ağında bulunan Kozan-Mansurlu İl yolu üzerinde meydana gelen heyelan alanının önceden yersel yöntemle üretilmiş halihazır harita sayısal arazi modeli ile heyelan sonrası İHA fotogrametrisi ile üretilen sayısal arazi modelinin karşılaştırması yapılmıştır. İHA kullanılarak üretilen heyelan alanı hâlihazır harita sayısal arazi modeli üzerinde 5 adet noktanın kotları, Microstation programı ile elde edilen sayısal arazi modeli üzerinden okunmuştur (Şekil 21).

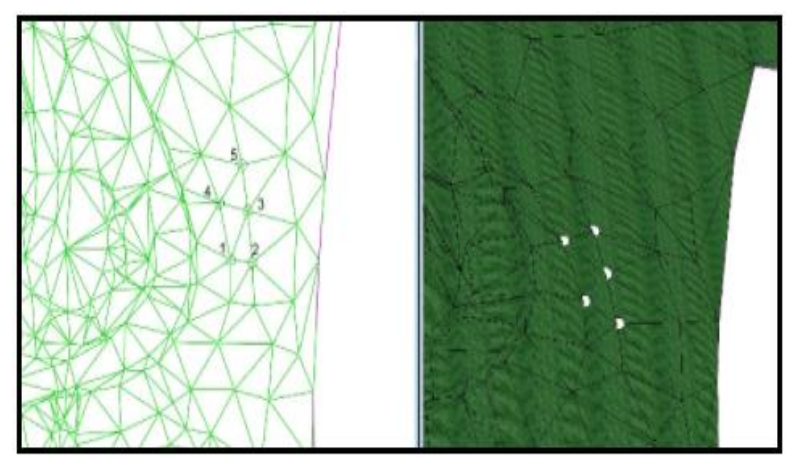

Şekil 21. SAM Microstation görünümü
Daha sonra bu noktaların yersel yöntemle üretilen sayısal arazi modeli üzerinde NetCAD yazılımı ile kotları üretilmiştir (şekil 22).

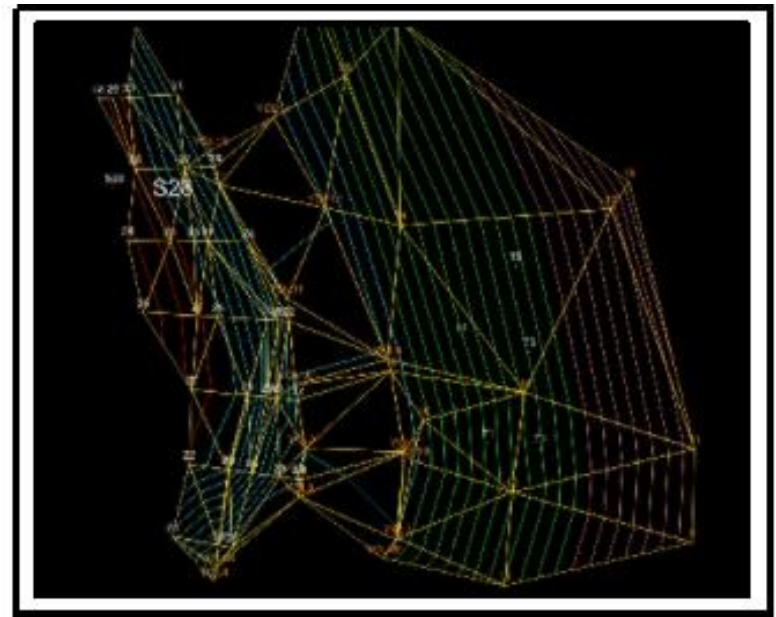

Şekil 22. SAM NetCAD görünümü

Yersel ve İHA fotogrametrisi yöntemiyle elde edilen sayısal arazi modeli karşılaştırmasında elde edilen kot farkları (Tablo 3.)'de verilmiştir.

Tablo 3. İki Yöntemle üretilen Sayısal Arazi Modelinin karşılaştırması

\begin{tabular}{|c|c|c|c|c|c|}
\hline Nokta No & $Y(\mathrm{~m})$ & $X(\mathrm{~m})$ & H(ort.) Yersel & H(ort.) jHA & Fark \\
\hline 1 & 465415.65 & 4170980.11 & 920.44 & 920.34 & 0.1 \\
\hline 2 & 465420.45 & 4170979.59 & 917.063 & 917 & 0.063 \\
\hline 3 & 465419.42 & 4170988.44 & 916.74 & 916.68 & 0.06 \\
\hline 4 & 465413.2 & 4170989.84 & 920.94 & 920.86 & 0.08 \\
\hline 5 & 465418.15 & 4170996.36 & 916.13 & 916.04 & 0.09 \\
\hline
\end{tabular}

\section{Sonuç ve öneriler}

Karayolu projelerinde yapım yaklaşık maliyet hesabını doğrudan etkileyen toprak işleri (kazıdolgu) miktarlarının doğru belirlenmesi gerekmektedir. Bu miktarların doğru hesaplanması, üretilen sayısal arazi modelinin doğruluğuna bağlıdır. İHA fotogrametrisi ile araziyi tam olarak yansıtabilen çok sayıda nokta üretildiğinden bu durum gerçeğe daha yakın bir hacim hesabı (kübaj) yapılmasına imkân sağlamaktadır.

Yersel yöntemle üretilmiş harita sayısal arazi modeli ile İHA teknikleri kullanılarak ürelen ahrita sayısal arazi modelinin kıyaslandığında kullanılan 5 adet test noktasının kotları arasındaki farklar 6-10 $\mathrm{cm}$ arasında olduğu görülmüş olup bu değerler Karayolları Yersel ve Fotogrametrik Yöntemle Üretilen Harita Teknik Şartnamesine göre kabul edilebilir sınırlar içerisinde kalmaktadır.

Belirlenen Karayolu proje güzergahlarında özelikle dağlık, dalgalı ve girilemeyen (yerel yöntemle ölçü imkânı olmayan) alanlar için İHA sistemlerinin kullanılması ve İHA sisteminin ortofoto ve sayısal harita üretilmesinde kullanılması 
için Karayolları Genel Müdürlüğün tarafından Yersel ve Fotogrametrik Harita İşlerine Ait Teknik Şartnamede düzenleme yapılması gerekmektedir.

Karayolu güzergâh projelerine altlık oluşturan halihazır haritaların klasik (geleneksel) yersel yöntemlere üretilmesi durumunda özellikle dağlık ve girilemeyen alanlarda can ve mal güvenliği açısından tehlike oluşturmakta olup, zaman kaybı ve yüksek maliyetler gerektirmektedir. Bu nedenle diğer alanlarda olduğu gibi karayolu projelerine altlık halihazır haritaların üretilmesinde de günümüz ileri teknolojisi olan İHA ların kullanılması önem arz etmektedir

Son zamanlarda karayolu proje güzergahlarında İHA fotogrametrisi tekniği ile elde edilen DTM (Dijital Terrain Model) sayısal arazi modelinin, yersel yöntemler ile üretilen halihazır haritanın DTM karşılaștırmasında, doğruluk derecesinin istenilen hassasiyette olduğu gözlemlenmiştir. $\mathrm{Bu}$ durum, İHA teknolojisi ile harita üretilmesinin önemini bir kez daha ortaya koymaktadır.

Tüm yatırım ve mühendislik hizmetlerinin (Kadastro, Mülkiyet Güvenlik, İmar, Ulaşım, Enerji, Maden, Tarım, Arkeoloji vb.) tümüne altlık olan haritanın üretilmesinde harita mühendislerinin önemli katkısı bulunmaktadır. Karayolu, maliyetli bir yatırım olması nedeni ile yapılacak işlerin sağlam ve güvenilir bir altlık üzerinde yürümesi gereklidir. Bu sebeple karayolu projelerine altlık olarak kullanılacak haritaların;

- Güvenilir bir yer kontrol ağına bağlanması

- 3 boyutlu olması hatta 4 . boyutun (zaman) dahil edilmesi

- Araziyi tam olarak yansitması

- İmalat ve işletme süresince ihtiyaca cevap verecek şekilde olması gerekir.

Karayollarında ve birçok mühendislik hizmetlerinde harita temel teşkil ettiğinden harita mühendisine de önemli görevler düşmektedir. Bunun farkına varılmalı ve bu işin önemi vurgulanmalıdır.

Geçmişte olduğu gibi günümüzde de karayolu projelerinde; ilk güzergâh projesinin belirlenmesi, buna bağlı olarak halihazır haritaların üretilmesi, yol projelerinin oluşturulması, kazı ve dolgu miktarlarının hesaplanması, kübaj hesaplarının yapılması_ projenin araziye aplikasyonu ve yapım aşamasında projenin araziye uygunluğunun kontrol edilmesinde harita mühendislerinin sorumlulukları çok fazladır. Çünkü bir karayolu projesinde ve projeye uygun imalatların yapılması hususlarında yapılacak hesap ve ölçü hataları, ekonomi ve zaman bakımından ciddi sorunlara yol açabilmektedir.

\section{Çatışma beyanı}

Herhangi bir çıkar çatıșması bulunmamaktadır.

\section{Kaynaklar}

Alptekin A \& Yakar M (2020). Heyelan bölgesinin İHA kullanarak modellenmesi. Türkiye İnsansız Hava Araçları Dergisi, 2(1), 17-21.

Alptekin A, Çelik M Ö, Doğan Y \& Yakar M (2019). Mapping of a rockfall site with an unmanned aerial vehicle.Mersin Photogrammetry Journal, 1(1), 12-16.

Höhle J (2009). DEM generation using a digital large format frame camera. Photogrammetric Engineering and Remote Sensing, 75 (1): 87-93.

KGM (2006):4 Stratejik plan (2006-2010)

Korumaz, A G., Dülgerler, O. N. \& Yakar, M. (2011). KÜLTÜREL MIRASIN BELGELENMESINDE DİJITAL YAKLAŞIMLAR. Selçuk Üniversitesi Mühendislik, Bilim ve Teknoloji Dergisi, 26 (3), 67-83.

Kök B V (2019) Karayolu Mühendisliği ve Tasarımı

Mirdan O \& Yakar M (2017). Tarihi eserlerin İnsansız Hava Aracı ile modellenmesinde karşılaşılan sorunlar. Geomatik, 2(3), 118-125.

Tercan E (2017). Karayolu Projelerinde İnsansız Hava Aracı ile Üretilen Sayısal Arazi Modelinin Değerlendirilmesi: Bucak-Kocaaliler Yolu Örneği. Mehmet Akif Ersoy Üniversitesi Fen Bilimleri Enstitüsü Dergisi 8(2): 172-183

URL-1 https://portal.kgm.gov.tr/Sayfalar/KGM/SiteTr /Root/default.aspx

URL-2: https://www.dji.com/phantom-4-pro

Uysal M, Toprak, A S \& Polat N (2015). İnsansız Hava Araçları ile Sayısal Arazi Modeli Üretimi. TUFAB VIII. Teknik Sempozyumu, 20-23 Mayıs 2015, Konya.

Ünel F B, Kuşak L, Çelik M Ö, Alptekin A \& Yakar M (2020). Kıyı Çizgisinin Belirlenerek Mülkiyet Durumunun İncelenmesi. Türkiye Arazi Yönetimi Dergisi, 2(1), 33-40.

Yakar M, Yıldız F \& Yılmaz H M (2005). Tarihi ve Kültürel Miraslarin Belgelenmesinde Jeodezi Fotogrametri Mühendislerinin Rolü. TMMOB Harita ve Kadastro Mühendisleri Odası, 10.

Yiğit A Y \& Uysal M (2021). Yüksek Çözünürlüklü İnsansız Hava Aracl (İHA) Görüntülerinden Karayolların Tespiti. Bitlis Eren Üniversitesi Fen Bilimleri Dergisi, 10(3), 1040-1054. 